\title{
Waste Management Regulation: Policy Solutions and Policy Shortcomings
}

\begin{abstract}
A model of packaging waste management is presented to explore the policy options available to governments to implement waste regulation in light of the Extended Producer Responsibility (EPR). Our model endogenises the packaging design as an additional determinant for the overall amount of waste jointly with consumers' sorting effort and producers' output decisions. The model shows that the policies that yield the first-best allocation may not find public support. Further, if the set of available policy instruments is limited, production and consumption of the good is likely to settle on a sub-optimal level even though the optimal allocation may be achievable. Finally, the model demonstrates that a landfill tax may actually increase landfill waste in the presence of tradable credits for recycling activities. The results shed light on some shortcomings of existing regulatory schemes such as the Producer Responsibility Obligations (Packaging Waste) Regulations of the UK.
\end{abstract}

Keywords: Extended Producer Responsibility; waste management; packaging design; recycling; landfill tax

JEL classification: Q28; H21 


\section{Introduction}

Waste management regulations motivated by the principle of Extended Producer Responsibility (EPR) -- i.e., the idea to hold producers responsible for products throughout their entire life cycles -- are intended to stimulate choices by the regulated producers that will reduce pollution generated by their products. The (EU) Council Directive 94/62/EC sets the minimum recovery and recycling targets for packaging waste for the EU member states, with the intention of motivating the regulated parties to reduce packaging waste. An EPR-driven packaging waste regulation requires producers to either treat (dispose or recycle) the packaging waste used for their products, or contract out the treatment to reprocessors and bear the cost. After more than a decade of implementing the required corresponding legislations at the national level, there are signs that the original intention is bearing fruit. For example, WRAP (2011) and WRAP (2012) report over one hundred case studies of so-called Courtauld Commitments 1, 2 and 3 in the UK grocery sector. Signatories are brand owners, manufacturers and retailers of household products who committed themselves to reduce packaging waste. Most of these studies report packaging design and method changes made by producers, resulting in a reduction in the use of packaging material.

Previous studies show that the first-best (socially optimal) waste management outcome can be characterised by a combination of a waste charge for consumers and an advanced disposable fee for producers or a recycling subsidy for consumers (e.g., Fullerton and Kinnaman, 1995; Shinkuma, 2003). ${ }^{1}$

As these papers, our study analyses the optimal policy strategies to implement waste management regulations but departs from them in several ways. First, in order to

\footnotetext{
${ }^{1}$ An advanced disposal fee means producers must pay a fee per unit of the product (and hence waste) produced and sold in anticipation of the resulting waste.
} 
capture EPR-motivated packaging waste management regulation we use a model that specifically incorporates and jointly determines three key choice variables: producers' packaging design effort, households' sorting effort, and output and consumption decisions. The vast majority of the previous literature, as cited above, endogenises some of these variables, but not all. However, all three variables are critical determinants of the amount of waste in reality. The overall amount of waste in our model therefore results from the decisions on these variables. ${ }^{2}$

Second, we take into account that policy solutions need not only be optimal but also politically feasible. In reality, policy makers may face difficulties in implementing theoretically optimal policies, for example, due to high administration costs or statutory barriers. But even optimal policy solutions that do not involve such problems may not end up on the political agenda. Politicians who are anxious about their re-election prospects will be wary of policies that are unlikely to attract public support. Any policy solution intended to implement EPR-driven waste regulation needs to comply with the general public's notion of producer responsibility to win sufficient political support. This dimension of the policy problem may lead to a serious additional challenge for policy makers.

Third, we evaluate the policy maker's options if not all policy instruments considered in our (general) theoretical analysis are available. This step is suggested by existing waste regulation as implemented, for example, in the UK.

Fullerton and $\mathrm{Wu}(1998)$ were among the first to address green design formally and spawned a by now considerable literature. They analyse the efficiency restoring

\footnotetext{
${ }^{2}$ In related research streams, the relation between packaging design and waste reduction is studied from different angles. For example, Aydinliyim and Pangburn (2012) point out that low-waste packaging may be inconvenient for consumers and require a compensating price discount. They show that an optimally chosen discount can lead to less waste while increasing profit and consumer surplus at the same time.
} 
policy response to various market failures. They show that, in the presence of the most common market failures, a subsidy to product recyclability or a subsidy to recycling by consumers in combination with other instruments such as a tax on packaging can yield the optimal outcome. Our model is related to theirs, but as opposed to their approach, we explicitly model sorting as an effort that causes disutility for households to capture that, in reality, waste reduction by households hinges critically on the time and energy spent on sorting through their waste to separate out recyclables. The volume of recycling then emerges through the interplay of sorting by households and packaging design choice by producers. Choe and Fraser (1999) point out how the explicit integration of household waste reduction effort into a model that is related to the approach by Fullerton and Wu can undermine previous conclusions. They show that the disutility associated with waste reduction gives households an incentive for illegal waste dumping that may countervail the incentive to reduce waste induced by downstream instruments such as a waste collection charge. ${ }^{3}$

Further work by Calcott and Walls $(2000,2005)$ also considers the product design (or product material mix) and ask which combinations of upstream and downstream instruments can implement an efficient "design for the environment" and

\footnotetext{
${ }^{3}$ The focus of the work by Fullerton and Wu (1998) and Choe and Fraser (1999) is on market failures due to the externalities of waste generation or failures that preclude the formation of a private market for recycling. Admittedly, they (and large part of the literature) do not consider that households may derive utility from home sorting despite the costs in terms of time and inconvenience and even if a central facility was available (Czajkowski, Kadziela and Hanley, 2014). Czajkowski, Hanley and Nyborg (2015) analyse different motivational drivers for sorting. They suggest that moral or intrinsic motivations play an important role in explaining households' willingness to sort. This suggests that the effectiveness of policy measures as discussed in the literature and also in this paper may differ substantially across sorters. Some households may only weakly react to fees or subsidies but respond rather strongly if their moral duty of engaging in recycling activities is emphasised instead.
} 
thus, recycling. ${ }^{4}$ Yet, again, these studies do not endogenise households' sorting effort. $^{5}$

Our model yields some disconcerting findings. First, policy makers may find it difficult to gain public support for both types of policy combinations that can yield the first-best allocation. The first policy solution is unlikely to satisfy the notion of an EPR-based regulation that the public is likely to hold because the solution requires subsidising producers without holding them physically or financially responsible for the cost of waste management at the end of their products' life cycles. The second policy solution may be perceived as unethical because the solution requires subsidising consumption (or production) of a polluting product. This argument carries over to our second finding. If downstream policy instruments such as a waste collection charge or a recycling subsidy are not available, the policy maker may be unable to achieve her recycling target unless she is willing to resort to the politically controversial measure of subsidising a polluting product. Finally, our analysis also points to a possible counterintuitive relationship between a landfill tax and landfill waste. An increase in the landfill tax may actually give rise to more landfill waste because the resulting higher volume of recycling activities generates a counterproductive effect. An increase in the landfill tax rate spurs recycling activities, which, in the presence of a mandatory packaging waste recycling target that is implemented through a system of tradeable recycling certificates as in the UK, results in a decrease in the costs for producers associated with recycling. However, this beneficial effect may be counteracted by the

\footnotetext{
4 "Green design" can refer to the disassembly properties, weight, material mix and, as in this paper, the packaging design.

${ }^{5}$ Aalbers and Volleberg (2008) model households as having to exert a separation effort to produce nearhomogeneous waste streams suitable for recycling but do not incorporate design improvements into their model. They conclude that a deposit-refund system provides optimal incentives for recycling and legal waste disposal.
} 
adverse incentive that lower recycling (production) costs have on producers' design efforts and household consumption. In the end, the overall amount of packaging waste may increase. These results shed light on some shortcomings of existing regulatory schemes such as the Producer Responsibility Obligations (Packaging Waste) Regulations of the UK.

The remainder of the paper is organised as follows. Section 2 presents the model and the first-best solution. The optimal policy mixes are derived in section 3 and the impact of the package design choice on the results is analysed. In sections 4 and 5 the model is adapted to reflect some features of existing waste regulations. Limitations regarding the available set of policy instruments and the effect of a landfill tax are examined. Section 6 concludes.

\section{The model and first-best solution}

The model considers three types of agents: consumers, producers of the packaged good, and the policy maker. The first-best solution is achieved when the policy maker maximises social welfare by choosing the three key variables: households' sorting effort $x, 0 \leq x \leq 1$, producers' packaging design effort $z, 0 \leq z \leq 1$, and output and consumption of the packaged good $q$.

$$
\underset{\{x, z, q\}}{\operatorname{Max}} W=U(q)+\omega-C(q)-F(z) q-[G(x)+\gamma(1-x)+\delta x](1-z) q .
$$

$U(q)$ is a concave utility function. The parameter $\omega$ denotes the consumer's endowment/income. $C(q)$ is the convex cost function of producing the packaged good. Given producers' packaging design $z,(1-z) q$ represents the total packaging waste for a 
given output level $q .{ }^{6}$ For simplicity, this expression also represents the total material used for packaging. $F(z)$ represents the cost of packaging design per output unit and is assumed to be convex. $G(x)$ represents the sorting disutility and is also assumed to be convex. Producers' packaging waste reduction/design effort $z$ and consumers' sorting effort $x$ jointly determine the amount of packaging waste to be recycled. $x(1-z) q$ represents packaging waste to be recycled, at the unit cost $\delta$, whereas $(1-x)(1-z) q$ represents the remaining waste that incurs the social cost of $\gamma$ per unit, comprising perunit waste management cost and negative externalities per unit waste. By assumption, $\gamma$ $>\delta$

Our model is based on the assumption of homogenous consumer preferences. Neither the utility function nor the endowment vary between households. Czajkowski, Kadziela and Hanley (2014) and Czajkowski, Hanley and Nyborg (2015), however, show that hourseholds typically show a large heterogeneity in preferences towards home sorting (see footnote 3 ). Random utility models offer ways to extend the model and incorporate preference heterogeneity. These models give rise to a variety of econometric specifications to analyse discrete choice decisions such as the decision to engage in recycling activities. ${ }^{7}$

\footnotetext{
${ }^{6}$ This expression, namely, waste reduction as a percentage of output, is consistent with the way packaging waste reductions are reported in various studies.

7 Preferences are modelled based on utility functions that include a deterministic component and a stochastic element to capture unobserved attributes or drivers for choice (Manski 1977, McFadden 1973). Different assumptions about the distribution of the stochastic element give rise to different choice models that link preferences to stated choices. Recent developments such as the Random Parameters model (McFadden and Train, 2000) and the Generalised Multinomial Logit Model (Fiebig, Keane, Louviere, and Wasi, 2010) provide flexible frameworks to integrate preference heterogeneity and therefore offer additional benefits to the researcher compared to the more restrictive traditional Multinomial Model (McFadden, 1973). Other approaches that have been used in the literature to represent preference heterogeneity in the stated choice context include latent class models and models that incorporate preference heterogeneity in the random utility component (Bhat, 1997).
} 
The policy maker's optimum $\left\{x^{*}, z^{*}, q^{*}\right\}$ is given by the following set of firstorder conditions:

$$
\begin{gathered}
\therefore G^{\prime}\left(x^{*}\right)=\gamma-\delta \\
\therefore F^{\prime}\left(z^{*}\right)=G\left(x^{*}\right)+\gamma\left(1-x^{*}\right)+\delta x^{*} \\
\therefore U^{\prime}\left(q^{*}\right)=C^{\prime}\left(q^{*}\right)+F\left(z^{*}\right)+\left[G\left(x^{*}\right)+\gamma\left(1-x^{*}\right)+\delta x^{*}\right]\left(1-z^{*}\right)
\end{gathered}
$$

Condition (1) balances out the marginal social cost and benefit of consumers' sorting efforts. Condition (2) implies that the marginal social cost of packaging waste reduction should be balanced against the marginal social benefit of lower sorting effort, the reduced costs of waste management, and recycling. Condition (3) equates marginal social cost and benefit in the product market. The corresponding amount of recycled packaging waste is $x *\left(1-z^{*}\right) q^{*}$.

In the case of a regulation-free environment, the representative producer maximises profit $\pi=p q-C(q)$, where $p$ is the market-given output price. This yields $p=C^{\prime}\left(q^{*}\right)$. Using a quasi-linear utility function, the representative consumer maximises $u=U(q)+\omega-p q$, where $\omega$ is the budget. This leads to $p=U^{\prime}\left(q^{*}\right)$. Obviously, without any regulation the optimal choice of the sorting effort level $(x)$ by consumers and packaging design effort level ( $z$ ) by producers are $x=z=0$ since they are costly activities. ${ }^{8}$

In what follows, we will analyse which waste management policy strategies can implement the first-best allocation. For this purpose, the model incorporates four policy instruments. $\tau$ denotes a waste charge (post-sorting if consumers pay; pre-sorting if

\footnotetext{
${ }^{8}$ We implicitly assume the type of local environments as seen in the UK, where local governments are in charge of the collection of residual waste and recyclables, the disposal of the former and processing of the latter, either by themselves or by hiring private firms. The costs of waste management incurred by the local governments are financed through the general Council Tax. Issues potentially relevant to the recycling markets such as imperfect competition and illegal dumping by the reprocessors are outside the scope of this study.
} 
producers pay), while $\phi$ is the sorting subsidy per unit of sorted recyclable. $t$ denotes the product tax per unit of $q$ consumed. Finally, $s$ denotes the consumption subsidy per unit of $q$. Although this is equivalent to a negative product tax, a different variable is used for notational clarity.

\section{Model solution}

\subsection{Fixed packaging design}

As discussed above, the joint determination of packaging design, sorting effort and consumption decisions has received little attention so far in the existing literature on waste regulation policies. Yet, all three elements influence the overall amount of waste and can be used as targets for economic policy interventions. Policy solutions proposed in previous work may therefore be in need of re-evaluation. In order to illustrate this, we will first follow the majority of the literature in treating the packaging design as exogenously given and derive and evaluate the optimal policy solutions under this assumption. In the next subsection, the packaging design will then be integrated into our model as a choice variable for producers.

Disregarding the packaging design as a choice variable can be represented in our model by assuming that the policy maker imposes $z=z^{*}$ on producers. To render our results comparable to the literature the policy maker is assumed to influence the consumers' and producers' decisions through a waste charge $\tau$ per unit of waste that can be collected from either party (denoted as $\tau_{D}$ or $\tau_{S}$ ), and a sorting subsidy to consumers $\phi$ per unit of recyclables sorted.

The producer's optimisation problem is now expressed as 


$$
\underset{\{q\}}{\operatorname{Max}} \pi=p q-C(q)-F\left(z^{*}\right) q-\tau_{S}\left(1-z^{*}\right) q
$$

which yields

$$
p=C^{\prime}(q)+F\left(z^{*}\right)+\tau_{S}\left(1-z^{*}\right) .
$$

The consumer now faces the following problem:

$$
\begin{aligned}
& \underset{\{q, x\}}{\operatorname{Max}} \quad u=U(q)+m-G(x)\left(1-z^{*}\right) q \\
& \text { s.t. } \quad p q+m+\tau_{D}(1-x)\left(1-z^{*}\right) q=\omega+\phi x\left(1-z^{*}\right) q
\end{aligned}
$$

which yields

$$
G^{\prime}(x)=\tau_{D}+\phi
$$

and

$$
p=U^{\prime}(q)-\left[\tau_{D}(1-x)-\phi x+G(x)\right]\left(1-z^{*}\right) .
$$

By setting $\tau_{D}+\phi=\gamma-\delta$ the policy maker can induce consumers to choose the optimal sorting effort level $x^{*}$ as given by Condition (1), equating the marginal social cost of sorting with its marginal benefit. This result, derived under the assumption of an invariant packaging design, corresponds to previous findings in the literature. For example, studies by Fullerton and Kinnaman (1995), Shinkuma (2003), and Ino (2011) imply that, in an ideal world (i.e., no illegal dumping) with recycling possibilities, the first-best outcome is characterised by $\tau_{D}+\phi=$ marginal external cost (MEC) of waste disposal. In our model, the MEC of waste disposal includes both the social cost of waste disposal and the reprocessing cost that would not be taken into account in a regulation free environment by either producers or consumers.

The optimal policy condition $\tau_{D}+\phi=\gamma-\delta$ implies that consumers can be induced to choose the sorting effort level $x^{*}$ (and hence $q^{*}$, as shown in the Appendix) 
by more than one combination of the available policy instruments $\tau_{D}$ and $\phi$. An overview is given in Table 1.

[Table 1 here]

Case 3-1a is likely to be perceived by many as being fully in line with the spirit of the EPR. Consumers receive the sorting subsidy $\phi=\gamma-\delta$ per unit of recyclables sorted, and producers pay the waste charge $\tau_{D}=\gamma$ per unit of (gross) waste produced. A recycling subsidy combined with an advanced waste disposal fee essentially is a deposit-refund system (Palmer et al., 1997).

In case $3-1 b$, consumers receive no subsidy for their sorting efforts and are charged for the remaining (i.e., post-sorting) waste. Meanwhile, producers are obliged to pay in advance for the recycling costs for the (gross) waste produced in the form of a waste charge.

Case 3-1c can be considered the least palatable to the general public because households must pay for the waste management cost and the recycling cost; hence, it is not consistent with the EPR principle. This policy solution implies that consumers choose the optimal effort level $x^{*}$ because the policy maker induces them to integrate the full costs of recycling and waste disposal in their decisions.

Even though consumers can be induced to choose the optimal sorting effort $x^{*}$, the three policy mixes (3-1a), (3-1b) and (3-1c) may not be implementable in practice. As long as the decision about $z$ is not left to the market, the policy maker will have to achieve the desired packaging waste reduction target by imposing $z=z^{*}$ on producers. 
However, prohibitively high information, monitoring and enforcement costs render the direct control of the design effort impossible.

\subsection{Packaging design as a choice variable}

We now turn to a more general formulation of the model by relaxing the simplifying assumption that the policy maker can set $z$. The packaging design can be taken into account as an additional driver for the overall amount of waste and, secondly, an additional policy channel for the policy maker in that the effort that producers spend on package design can be stimulated through policy interventions.

The packaging design choice will now be treated as part of the producers' optimisation problem. Hence, all three variables that determine the amount of waste-production and consumption $q$, sorting effort $x$, and design effort $z$--are controlled by the agents on the supply and demand side of the packaged good market, and their level will be determined jointly and endogenously in the model. In this sense, decision making is fully decentralised now.

The available set of policy instruments now consists of a sorting subsidy $\phi$ per unit of recyclables sorted, a waste charge $\tau$ or subsidy $\sigma$ that that can be collected from either producers or consumers, and a product tax $t$ or subsidy $s$ per unit of the good.

The producer's maximisation problem now reads

$$
\underset{\{q, z\}}{\operatorname{Max}} \pi=p q-C(q)-F(z) q+\mathrm{A} ; \mathrm{A}=-\tau(1-z) q \text { or } \sigma z q
$$

Two different policy mixes can induce the desired outcome, as shown in Table 2. The available policy strategies can be described as carrot $(\sigma)$ or stick $(\tau){ }^{9}$

\footnotetext{
${ }^{9}$ Both cases illustrate the Tinbergen principle (Tinbergen, 1967): each policy target is addressed by a single policy instrument.
} 
[Table 2 here]

Case 3-2a: the "carrot" case.

The first-order conditions for the producers are

$$
\begin{aligned}
& \pi_{z}=-F^{\prime}(z) q+\left[G\left(x^{*}\right)+\gamma\left(1-x^{*}\right)+\delta x^{*}\right] q=0 \\
& \pi_{q}=p-C^{\prime}(q)-F(z)+\left[G\left(x^{*}\right)+\gamma\left(1-x^{*}\right)+\delta x^{*}\right] z=0
\end{aligned}
$$

while the consumers maximise

$$
\begin{gathered}
\operatorname{Max}_{\{q, x\}} u=U(q)+\omega-p q-G(x)(1-z) q+(\gamma-\delta) x(1-z) q \\
-\left[G\left(x^{*}\right) z^{*}+(\delta-\gamma) x^{*} z^{*}+\gamma\right] q
\end{gathered}
$$

which yields

$$
\begin{gathered}
u_{x}=\left[-G^{\prime}(x)+(\gamma-\delta)\right](1-z) q=0 \\
u_{q}=U^{\prime}(q)-p+[-G(x)+(\gamma-\delta) x](1-z) \\
-\left[G\left(x^{*}\right) z^{*}+(\delta-\gamma) x^{*} z^{*}+\gamma\right]=0
\end{gathered}
$$

(7a) yields (2), and (9a) yields (1). In equilibrium (8a) and (10a) yield Condition (3). In case 3-2a, producers are rewarded for their efforts to improve their packaging design through a subsidy $\sigma$, and consumers are rewarded for their sorting efforts through a subsidy $\phi$. In addition, a product tax $t$ is imposed. The need for directly subsidising producers' efforts to reduce pollution through $\sigma$ raises the question of whether this policy mix satisfies people's perception of an EPR-driven regulation that is supposed to hold producers responsible. As it is irrelevant for efficiency on which side of the 
market $t$ is imposed, assigning the statutory liability of the product tax to producers (and not consumers) may help to address this problem. ${ }^{10}$

Case 3-2b: the "stick" case.

The first-order conditions become

$$
\begin{aligned}
& \pi_{z}=-F^{\prime}(z) q+\left[G\left(x^{*}\right)+\gamma\left(1-x^{*}\right)+\delta x^{*}\right] q=0 \\
& \pi_{q}=p-C^{\prime}(q)-F(z)-\left[G\left(x^{*}\right)+\gamma\left(1-x^{*}\right)+\delta x^{*}\right](1-z)=0
\end{aligned}
$$

Meanwhile, consumers face

$$
\begin{gathered}
\underset{\{q, x\}}{\operatorname{Max}} u=U(q)+\omega-p q-G(x)(1-z) q+(\gamma-\delta) x(1-z) q \\
+\left[G\left(x^{*}\right)+(\delta-\gamma) x^{*}\right]\left(1-z^{*}\right) q
\end{gathered}
$$

which yields

$$
\begin{gathered}
u_{x}=\left[-G^{\prime}(x)+(\gamma-\delta)\right](1-z) q=0 \\
u_{q}=U^{\prime}(q)-p+[-G(x)+(\gamma-\delta) x](1-z)+\left[G\left(x^{*}\right)+(\delta-\gamma) x^{*}\right]\left(1-z^{*}\right) \\
=U^{\prime}(q)-p=0 \quad \text { given (7b) and } 9(\mathrm{~b}) .
\end{gathered}
$$

(7b) and (9b) yield Condition (2) and (1), respectively, and (8b) and (10b) yield

Condition (3). The optimal policy is represented by the combination of three

instruments (following from the three FOCs). On the one hand, producers must pay the waste charge $\tau$ that will increase their marginal costs (to ensure that producers take account of the marginal external cost of waste generated by their product). On the other hand, consumers are given subsidies for their sorting efforts $\phi$ (where the "reward" is equal to the marginal social (net) benefit of recycling). In addition, the government pays a unit subsidy $s$ for $q$ ( $s$ can be interpreted a reward for producers' effort to reduce

\footnotetext{
${ }^{10}$ EPR is an application of the Polluter Pays Principle. We refer to EPR throughout the paper as it is commonly used in the waste management context. Hence, assigning the statutory liability of the product tax to producers would align the solution with the Polluter Pays Principle.
} 
waste which is equal to the marginal social (net) benefit of reduced waste). ${ }^{11}$ It has been pointed out that a tax on virgin resources should be combined with a subsidy for final goods to correct the inefficiently low level of production, consumption, and garbage (Palmer and Walls, 1994). This model yields a qualitatively similar result for a tax on packaging waste. On the one hand, in line with the idea of an EPR-driven regulation, producers must pay the waste charge. But on the other hand, the public may resist the idea that consumption (or production) of polluting products are subsidised, making it politically difficult to implement such a subsidy in reality.

Our results so far contrast with those of Choe and Fraser (1999), whose model also endogenises product/packaging design, output, and sorting effort. There are two notable differences between their model and ours. First, in their model it is assumed that both producers and household simultaneously choose the product/ packaging design (as is the case in Fullerton and $\mathrm{Wu}, 1998$ ). Second, we consider atomistic agents on both sides of the market, i.e. agents are price takers. When buying a product, buyers face a take-it-or-leave-it offer for both the good itself and the packaging. ${ }^{12}$ Of course, the equilibrium price of the good is a function of the product design variable. As demonstrated by the first-order conditions for both cases, the design variable $z$ affects $p$ through both producers' and consumers' decisions. For producers, design efforts are costly but are also beneficial in view of the policy variables imposed (tax on waste or subsidy for the efforts made). For consumers, the packaging design affects their waste

\footnotetext{
${ }^{11}$ The sign depends on the sign of $G\left(x^{*}\right)+(\delta-\gamma) x^{*}$. If we assume that the disutility of sorting is very high and $\gamma$ relatively low, then $G\left(x^{*}\right)+(\delta-\gamma) x^{*}>0$. See the Appendix for more details.

${ }_{12}$ Another significant difference is that Choe and Fraser (1999) consider two policy instruments (a tax on gross waste and a waste charge on net waste) in choosing three variables. We demonstrate that, following Tinbergen (1967), the first-best allocation is (theoretically) feasible, with the necessary number of policy instruments employed. It can be shown that, with an additional policy instrument of a per-unit consumption subsidy for households, Choe and Fraser's (1999) model (without illegal dumping) can yield the first-best allocation without giving the pricing power to firms or households, i.e., in a perfectly competitive market structure.
} 
production, and in response to the policy variables (waste charge or sorting subsidy) they will adjust their consumption decisions, which affects the market price of the product.

Figure 1 depicts the equilibrium outcomes presented so far in a demand-supply context.

[Figure 1 here]

In both cases, the amount of recycled material is given by $x^{*}\left(1-z^{*}\right) q^{*}$. The total net benefit generated by this market and the distribution of consumer versus producer surplus remain unchanged. This means that, provided that the three policy instruments can be implemented, the additional policy target of optimal packaging design effort can be achieved without any efficiency loss or re-distributional consequences (within the partial equilibrium context).

Notice that both policy options embody a form of a deposit-refund system. The "carrot" policy mix is a deposit-refund system; the consumers of the packaged product pay the deposits, and then receive post-consumption refunds after sorting efforts have been made. The "stick" policy mix can also be interpreted as a deposit-refund system, if the product subsidy is given to the producers (with $\tau$ being the deposit).

Yet, the "carrot" and "stick" policies may be difficult to implement for political reasons. The "stick" policy mix holds producers liable for waste generated, but it requires a consumption subsidy for the polluting good. This is unlikely to appeal to the general public. The "carrot" policy mix embodies what people normally consider a deposit-refund system, in that those who pay the deposits also receive refunds. 
However, it requires a subsidy for producers and therefore may not correspond to the general public's notion of an EPR-driven regulation. Meanwhile, in contrast to the "stick" policy, the "carrot" policy does not require a consumption subsidy for the polluting good. Instead, the polluting good is to be taxed, and shifting the statutory tax liability for the product tax to the producers may improve the acceptance of this policy by the general public. Implementing either of the two optimal policies is therefore associated with a substantial challenge for the policy maker's communication policy. This complication can easily be overlooked if the packaging design is not treated as a deliberate choice by the supply side of the market - as a comparison with the results derived in the previous subsection underscores.

\section{Unavailability of downstream instruments}

In the theoretical analysis we have assumed that a broad variety of policy instruments are available to the policy maker. However, this may not be the case in reality. For example, the policy maker may be unable to provide consumers with a sorting subsidy $\phi$ due to legal restrictions, high administrative cost, etc. How can the policy maker react?

The model implies that on the one hand the policy maker could still induce the producers to choose the packaging design effort $z^{*}$ via a producer waste charge $\tau=$ $G\left(x^{*}\right)+\gamma\left(1-x^{*}\right)+\delta x^{*} ;$ on the other hand, the model also implies that without any subsidy consumers exert zero sorting effort.

However, in reality, even without a sorting subsidy people sort waste to some extent, possibly because they derive utility from good acts. ${ }^{13}$ For example, Viscusi et

\footnotetext{
${ }^{13}$ See Kinnaman (2006) for the summary of literature on recycling services and utility benefit.
} 
al. (2011) report that in the US fifty eight per cent of the households living in states without any deposit-refund system still recycle eight or more out of ten bottles. Brekke et al. (2010) report that people take on recycling activities out of moral responsibility, though they view such activities as a burden. Czajkowski et al. (2014) present evidence for Poland that households prefer to sort waste themselves over having their unsorted waste collected at no extra cost to be sorted at a specialised facility.

Let us therefore assume that there is a default sorting level $x_{0}$ that is executed by consumers at a given cost, for example out of a sense of moral duty. By assumption, $x_{0}<x^{*}$. What is the likely outcome regarding the packaged good if consumers are willing to make the sorting effort $x_{0}$ ? Are we to produce and consume too much or too little? Two opposing forces have to be considered. On the one hand producers incur the additional cost of the waste charge, which pushes down the production of the polluting good. On the other hand consumers are willing to exert a sorting effort up to $x_{0}$. The answer is provided in Figure 2.

\section{[Figure 2 here]}

The equilibrium outcome is given by $(z, x, q)=\left(z^{*}, x_{0}, q^{\prime}\right)$ where $x_{0}<x^{*}$ and $q^{\prime}<q^{*}$. Without a policy instrument that affects households' behaviour directly, any attempt to stimulate producers' packaging design effort through a waste charge will lead to an inefficiently low level of production. As pointed out in the previous section, an appropriately chosen (but potentially controversial) subsidy $s$ per unit of the good can correct the inefficiently low level of production and consumption of the packaged 
good, thus bringing the equilibrium to point $E_{1}$, i.e., the optimal resource allocation.

Yet, as discussed above, such a measure may be subject to considerable political implementation problems.

An additional conclusion, which is of particular relevance for the UK for example, can be drawn. Local authorities in the UK are not allowed by law to impose direct variable (volume- or weight-based) or fixed waste charges on households. ${ }^{14}$ Yet, the non-availability of waste charges as a policy instrument is innocuous with respect to the implementation of the first-best allocation. The ability of British policy makers to reach the optimal waste allocation is therefore not impaired according to our model.

\section{$5 \quad$ Effects of a landfill tax}

The model in this paper can also be used to explore the effects of a landfill tax that has become a commonly observed waste management tool in Europe since the EU Landfill Directive of 1999. A landfill tax can be understood as an increase in the operational cost of waste disposal and can therefore be captured by $\gamma$ in this model. The analysis of the model yields the expected results, that is, whichever policy mix (carrot or stick) we employ, it is straightforward to show that $d z * / d \gamma>0, d x * / d \gamma>0$, and $d q * / d \gamma<0$ (see the Appendix). In other words, an increase in the waste management costs due to a higher landfill tax results in increased sorting activities and design efforts together with reduced consumption of the good. ${ }^{15}$

\footnotetext{
${ }^{14}$ Charging consumers directly for disposal costs may give rise to illegal waste disposal. A disposal fee for consumers therefore may need to be combined with costly monitoring and prevention activities (see Choe and Fraser, 1999, and Ino, 2011, for waste reduction models that incorporate monitoring cost) or a better provision of waste treatment facilities. Ichinose and Yamamoto (2011) point to the latter and report based on data for Japan that an increase in waste treatment facilities has a dampening effect on illegal dumping.

${ }^{15} \mathrm{An}$ increase in $\gamma$ can also be interpreted as an increase in the opportunity cost of landfill space, an interesting subject to explore for economies in which landfill space has become scarce (e.g., Europe).
} 
However, this model can also be used to illustrate the mechanism behind a counter-intuitive proposition derived by Matsueda and Nagase (2012). They show that an increase in the landfill tax rate could result in an increase in landfill waste if the landfill tax is implemented along with a mandatory recycling target. This can be illustrated with the help of the Producer Responsibility Obligations (Packaging Waste) Regulations (PWRegs), an EPR-driven regulation implemented in the UK in 1997. Under the PWRegs producers of packaged goods must purchase tradable credits called Packaging Recovery Notes (PRNs) from registered reprocessors as proof of their fulfilling the mandatory recycling target regarding packaging waste.

Such a counter-intuitive result arises if an additional determinant for the parameter $\delta$ is taken into account. The model presented here implies that $d z^{*} / d \delta>0$, $d x * / d \delta<0$, and $d q * / d \delta<0$ (see the comparative static analysis for case 3-2 in the Appendix). These results are intuitive, if an increase in $\delta$ is interpreted as recycling activities becoming more costly; it stimulates producers' packaging design efforts to reduce the recyclable waste but discourages consumers' sorting efforts. In addition, the higher reprocessing cost will reduce the production and consumption of the packaged good. However, against the backdrop of the PWReg, $\delta$ can be understood as being dependent on the price of the PRN ( $\left.\mathrm{P}_{\mathrm{PRN}}\right)$. It can now be concluded that an increase in the landfill tax will reduce $\mathrm{P}_{\mathrm{PRN}}$. As intended, the benefit and therefore the volume of recycling activities grows after the tax on landfill waste has been raised. This, however, will lead to a drop in $\mathrm{P}_{\mathrm{PRN}}$ due to the increase in supply of PRNs and hence a decrease in $\delta$ (see Matsueda and Nagase, 2012). Cheaper PRNs in turn will decrease production costs. Therefore, an increase in the landfill tax will affect producers' packaging design efforts negatively through its effect on $\mathrm{P}_{\mathrm{PRN}}$ and thus $\delta$ and tend to increase the 
production and consumption of the packaged good on the one hand. On the other hand, a decrease in $\delta$ stimulates consumers' sorting efforts as discussed above. The overall effect on the landfill waste, represented by $(1-x)(1-z) q$, depends on which effect dominates.

\section{Conclusion}

The model in this paper extends the existing waste regulation literature by jointly endogenising producers' packaging design effort, the production and consumption of the packaged good and households' sorting effort as determinants of the overall amount of waste and possible targets for policy interventions.

The model shows that two policy combinations can yield the optimal packaging waste management. The consumers of the packaged product pay the product tax and are rewarded for their sorting efforts. Producers on the other hand receive a reward (subsidy) for their packaging design effort without any penalty imposed on their activities. This is likely to be inconsistent with the general public's notion of an EPRbased regulation so that the "carrot" policy mix may fail to win public support. Making producers liable for the product tax may ameliorate such a negative view. Under the “stick" policy mix, producers are held liable for the packaging waste generated; however, this policy mix requires a product subsidy for a polluting good, which may send a confusing signal to the general public. In short, the theoretical policy solutions are one thing; implementation of these alternatives in reality is another.

Similar complications arise if the set of available policy instruments is limited. Production and consumption of the packaged good are likely to settle on a sub-optimal 
level if, for example, a sorting subsidy to households is not available due to administrative or legal reasons, as compensating measure may not attract enough support from the general public. Redirecting sorting activities from households to other agents (e.g., reprocessors) may be a better solution in this case, especially as kerbside recycling programmes have to be run at high operating costs in general. ${ }^{16}$ Further complications can arise through the effect that changes in the landfill tax have on the volume of recycling activities. In the presence of tradable credits that producers are obligated to acquire as evidence of packaging waste recycling, an increase in the landfill tax can actually give rise to more landfill waste.

The model in this paper follows a static approach. Complementing this study by modelling the dynamic effects of packaging design improvement is an interesting avenue for future research. A better packaging design often means that not only less material is used. It can also make it easier to de-assemble the package for recycling. Such a change is likely to result in a decrease in the disutility of sorting effort and an increase in the default sorting level over time. Such dynamic effects may help explain, for example, why the UK has been successful in meeting its packaging waste recycling targets, despite the lack of a waste charge for or sorting subsidy to households. ${ }^{17}$

\footnotetext{
${ }^{16}$ Empirical studies have found that curb-side recycling operations tend to incur net costs, and households' demand for waste disposal is price-inelastic (Kinnaman, 2006). Higher-income households are likely to be less inclined to exert sorting efforts and more likely to be willing to pay for alternative means (Huhtala, 2010). Rewarding reprocessors for sorting and recycling activities have advantages such as lower transaction costs and better incentivizing of actual recycling (Walls, 2011).

${ }^{17}$ The regulated parties (sellers of packaged goods and providers of packaging services) are aware that whether they can achieve the recycling target imposed by the Defra depends critically on the level of $x_{0}$. As early as 2005, Valpak expressed concerns about meeting the required targets due to the fact that recycling activities ultimately depend on local authorities' recovery activities which depend on the sorting effort of households (Valpak, 2005).
} 


\section{Appendix}

Case 3-1a:

The first-order conditions become

$$
\begin{aligned}
& \pi_{q}=p-C^{\prime}(q)-F\left(z^{*}\right)-\gamma\left(1-z^{*}\right)=0 \\
& u_{x}=\left[-G^{\prime}(x)+(\gamma-\delta)\right]\left(1-z^{*}\right) q=0 \\
& u_{q}=U^{\prime}(q)-p-[-(\gamma-\delta) x+G(x)]\left(1-z^{*}\right)=0
\end{aligned}
$$

(5a) yields Condition (1). (4a) and (6a) yield Condition (3), hence we obtain $q=$ $q^{*}$. Consequently, (2) is satisfied as well.

Case 3-1b:

The first-order conditions become

$$
\begin{aligned}
& \pi_{q}=p-C^{\prime}(q)-F\left(z^{*}\right)-\delta\left(1-z^{*}\right)=0 \\
& u_{x}=\left[-G^{\prime}(x)+(\gamma-\delta)\right]\left(1-z^{*}\right) q=0 \\
& u_{q}=U^{\prime}(q)-p-[(\gamma-\delta)(1-x)+G(x)]\left(1-z^{*}\right)=0
\end{aligned}
$$

(5b) yields Condition (1), and (4b) and (6b) yield Condition (3).

Case 3-1c:

The first order conditions become

$$
\begin{aligned}
& \pi_{q}=p-C^{\prime}(q)-F\left(z^{*}\right)=0 \\
& u_{x}=\left[-G^{\prime}(x)+(\gamma-\delta)\right]\left(1-z^{*}\right) q=0 \\
& u_{q}=U^{\prime}(q)-p-\left[\left(1-x^{*}\right)+\delta x^{*}+G\left(x^{*}\right)\right]\left(1-z^{*}\right)=0
\end{aligned}
$$

(5c) yields Condition (1), and (4) and (6c) yield Condition (3). 
Case 3-2:

In equilibrium the following set of conditions hold:

$$
\begin{aligned}
& -F^{\prime}\left(z^{*}\right)+\left[G\left(x^{*}\right)+\gamma\left(1-x^{*}\right)+\delta x^{*}\right]=0, \\
& -G^{\prime}\left(x^{*}\right)+(\gamma-\delta)=0, \text { and } \\
& U^{\prime}\left(q^{*}\right)-C^{\prime}\left(q^{*}\right)-F\left(z^{*}\right)-\left[G\left(x^{*}\right)+\gamma\left(1-x^{*}\right)+\delta x^{*}\right]\left(1-z^{*}\right)=0 .
\end{aligned}
$$

Totally differentiating the three functions yields

$$
J\left[\begin{array}{c}
d z^{*} \\
d x^{*} \\
d q^{*}
\end{array}\right]=\left[\begin{array}{c}
-\left(1-x^{*}\right) d \gamma-x^{*} d \delta \\
-d \gamma+d \delta \\
\left(1-z^{*}\right)\left(1-x^{*}\right) d \gamma+\left(1-z^{*}\right) d \delta
\end{array}\right]
$$

where the Jacobian matrix $J$ is given by

$$
J=\left[\begin{array}{ccc}
-F^{\prime \prime}\left(z^{*}\right) & G^{\prime}\left(x^{*}\right)-(\gamma-\delta) & 0 \\
0 & -G^{\prime \prime}\left(x^{*}\right) & 0 \\
G\left(x^{*}\right)+\gamma\left(1-x^{*}\right) & -\left[G^{\prime}\left(x^{*}\right)-(\gamma-\delta)\right]\left(1-z^{*}\right) & U^{\prime \prime}\left(q^{*}\right)-C^{\prime \prime}\left(q^{*}\right) \\
+\delta x^{*}-F^{\prime}\left(z^{*}\right) &
\end{array}\right]
$$

and $|J|<0$. (Note that this matrix is corresponds to the Hessian matrix of the social planner's optimisation, hence it is a negative definite.) The matrix $J$ can be simplified to be:

$$
J=\left[\begin{array}{ccc}
-F^{\prime \prime}\left(z^{*}\right) & 0 & 0 \\
0 & -G^{\prime \prime}\left(x^{*}\right) & 0 \\
0 & 0 & U^{\prime \prime}\left(q^{*}\right)-C^{\prime \prime}\left(q^{*}\right)
\end{array}\right]
$$

Hence we have

$$
\begin{aligned}
& \frac{d z^{*}}{d \gamma}=\frac{\left(1-x^{*}\right) G^{\prime \prime}\left(U^{\prime \prime}-C^{\prime \prime}\right)}{|J|}>0, \\
& \frac{d x^{*}}{d \gamma}=\frac{F^{\prime \prime}\left(U^{\prime \prime}-C^{\prime \prime}\right)}{|J|}>0,
\end{aligned}
$$




$$
\begin{aligned}
& \frac{d q^{*}}{d \gamma}=\frac{F^{\prime \prime} G^{\prime \prime}\left(1-z^{*}\right)\left(1-x^{*}\right)}{|J|}<0, \\
& \frac{d z^{*}}{d \delta}=\frac{x^{*} G^{\prime \prime}\left(U^{\prime \prime}-C^{\prime \prime}\right)}{|J|}>0, \\
& \frac{d x^{*}}{d \delta}=\frac{-F^{\prime \prime}\left(U^{\prime \prime}-C^{\prime \prime}\right)}{|J|}<0, \text { and } \\
& \frac{d q^{*}}{d \delta}=\frac{F^{\prime \prime} G^{\prime \prime}\left(1-z^{*}\right)}{|J|}<0 .
\end{aligned}
$$

Sign of subsidy s for case 3-2b:

$s=\left[G\left(x^{*}\right)+(\delta-\gamma) x^{*}\right]\left(1-z^{*}\right)$, so the sign of $s$ depends on the sign of the expression in brackets, $G\left(x^{*}\right)+(\delta-\gamma) x^{*}$. At the first-best allocation, $G^{\prime}\left(x^{*}\right)=\gamma-\delta$ (see the figure below).

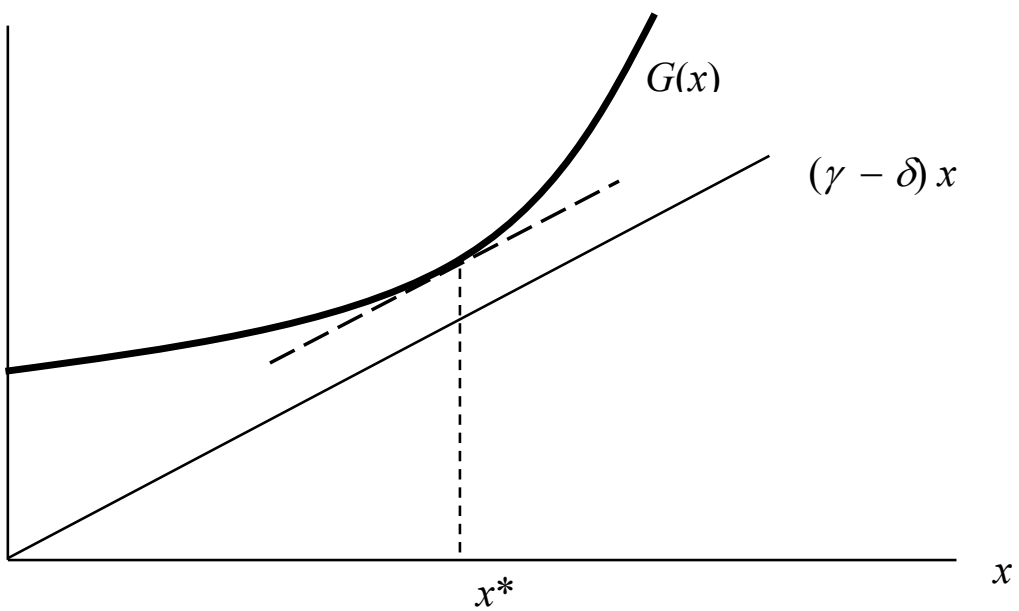

If low sorting efforts (low values of $x$ ) do not cause too much disutility, then $G\left(x^{*}\right)<(\gamma$ $-\delta) x^{*}$ will hold at $x^{*}$. Whereas, if the disutility of sorting $G(x)$ is very high already for low values of $x$, then as shown above, we have $G\left(x^{*}\right)>(\gamma-\delta) x^{*}$. 


\section{References}

AALBERS, R. F. T. and VOLLEBERGH, H. R. J. (2008). An Economic Analysis of Mixing Wastes. Environmental and Resource Economics, 39, 311-330.

AYDINLIYIM, T. and PANGBURN, M. S. (2012). Reducing Packaging Waste and Cost via Consumer Price Discounts. Design Science, 43, 1063-1089.

BHAT, C. 1997. Covariance heterogeneity in nested logit models: Econometric structure and application to intercity travel. Transportation Research Part B, 31, $11-21$.

BREKKE, K. A., KIPPERBERG, G. and NYBORG, K. (2010). Social Interaction in Responsibility Ascription: The Case of Household Recycling. Land Economics, 86, 766-784.

CALCOTT, P. and WALLS, M. (2000). Can Downstream Waste Disposal Policies Encourage Upstream 'Design for Environment'? American Economic Review, 90, 233-237.

CALCOTT, P. and WALLS, M. (2005). Waste, Recycling, and 'Design for Environment': Roles for Markets and Policy Instruments. Resource and Energy Economics, 27, 287-305.

CHOE, C. and FRASER, I. (1999). An Economic Analysis of Household Waste Management. Journal of Environmental Economics and Management, 38, 234246.

CZAJKOWSKI, M., HANLEY, N. and NYBORG, K. (2015). Social Norms, Morals and Self-Interest as Determinants of Pro-environment Behavious: The Case of Household Recycling. Environmental and Resource Economics, doi:10.1007/s10640-015-9964-3.

CZAJKOWSKI, M., KADZIELA, T and HANLEY, N. (2014). We want to sort! Assessing households' preferences for sorting waste. Resource and Energy Economics, 36, 290-306.

FIEBIG, D, KEANE, M., LOUVIERE, J., and WASI, N. (2010). The Generalized Multinomial Logit Model: Accounting for Scale and Coefficient Heterogeneity. Marketing Science 29, 393-421.

FULLERTON, D. and KINNAMAN, T. C. (1995). Garbage, Recycling, and Illicit Burning or Dumping. Journal of Environmental Economics and Management, 29, 78-91.

FULLERTON, D. and WU, W. (1998). Policies for Green Design. Journal of Environmental Economics and Management, 36, 131-148. 
HUHTALA, A. (2010). Income effects and the inconvenience of private provision of public goods for bads: The case of recycling in Finland. Ecological Economics, $69,1675-1681$.

ICHINOSE, D. and YAMAMOTO, M. (2011). On the relationship between the provision of waste management service and illegal dumping. Resource and Energy Economics, 33, 79-93.

INO, H. (2011). Optimal Environmental Policy for Waste Disposal and Recycling When Firms Are Not Compliant. Journal of Environmental Economics and Management, 62, 290-308.

KINNAMAN, T. 2006. Policy Watch: Examining the Justification for Residential Recycling. Journal of Economic Perspectives, 20, 219-232.

MANSKI, C. (1977). The Structure of Random Utility Models. Theory and Decision, 8, 229-254

MATSUEDA, N. and NAGASE, Y. (2012). An Economic Analysis of the Packaging Waste Recovery Note System in the UK. Resource and Energy Economics, 34, 669-679.

McFADDEN, D. (1973). Conditional Logit Analysis of Qualitative Choice Behavior, in P. Zarembka (ed.), Frontiers in Econometrics, New York, Academic Press, 105142.

McFADDEN, D. and TRAIN, K. (2000). Mixed MNL Models of Discrete Response. Journal of Applied Econometrics, 15, 447-470.

PALMER, K., SIGMAN, H. and WALLS, M. (1997). The Cost of Reducing Municipal Solid Waste. Journal of Environmental Economics and Management, 33, 128150.

PALMER, K. and WALLS, M. (1994). Materials Use and Solid Waste Disposal: An Evaluation of Policies. Resources For the Future Discussion Paper 95-02, Washington, DC.

SHINKUMA, T. (2003). On the Second-Best Policy of Household's Waste Recycling. Environmental and Resource Economics, 24, 77-95.

TINBERGEN, J. (1967). Economic Policy: Principles and Design, Amsterdam, North Holland Publishing Company.

VISCUSI, W. K., HUBER, J. and BELL, J. (2011). Promoting Recycling: Private Values, Social Norms, and Economic Incentives. American Economic Review, 101, 65-70.

VALPAK (2005). PackFlow 2008. UK compliance with the 2008 targets of the European Packaging \& Packaging Waste Directive. Summary Report and 
Recommendations. [Online]. Available: http://www.packagingfedn.co.uk/ images/reports/Packflow_report05.pdf [Accessed 2015-01-14].

WALLS, M. (2011). Deposit-Refund Systems in Practice and Theory. Resources For the Future Discussion Paper 11-47, Washington, DC.

WRAP (2011). Courtauld Commitment 1 (2005-2010) case studies. [Online]. Available: http://www.wrap.org.uk [Accessed 2016-04-01].

WRAP (2012). Courtauld Commitment 2 Voluntary Agreement 2010-2012 Signatory Case Studies and Quotes [Online].

Available: http://www.wrap.org.uk/sites/files/wrap/CC2 [Accessed 2013-04-22]. 
Figure 1. Packaged good market

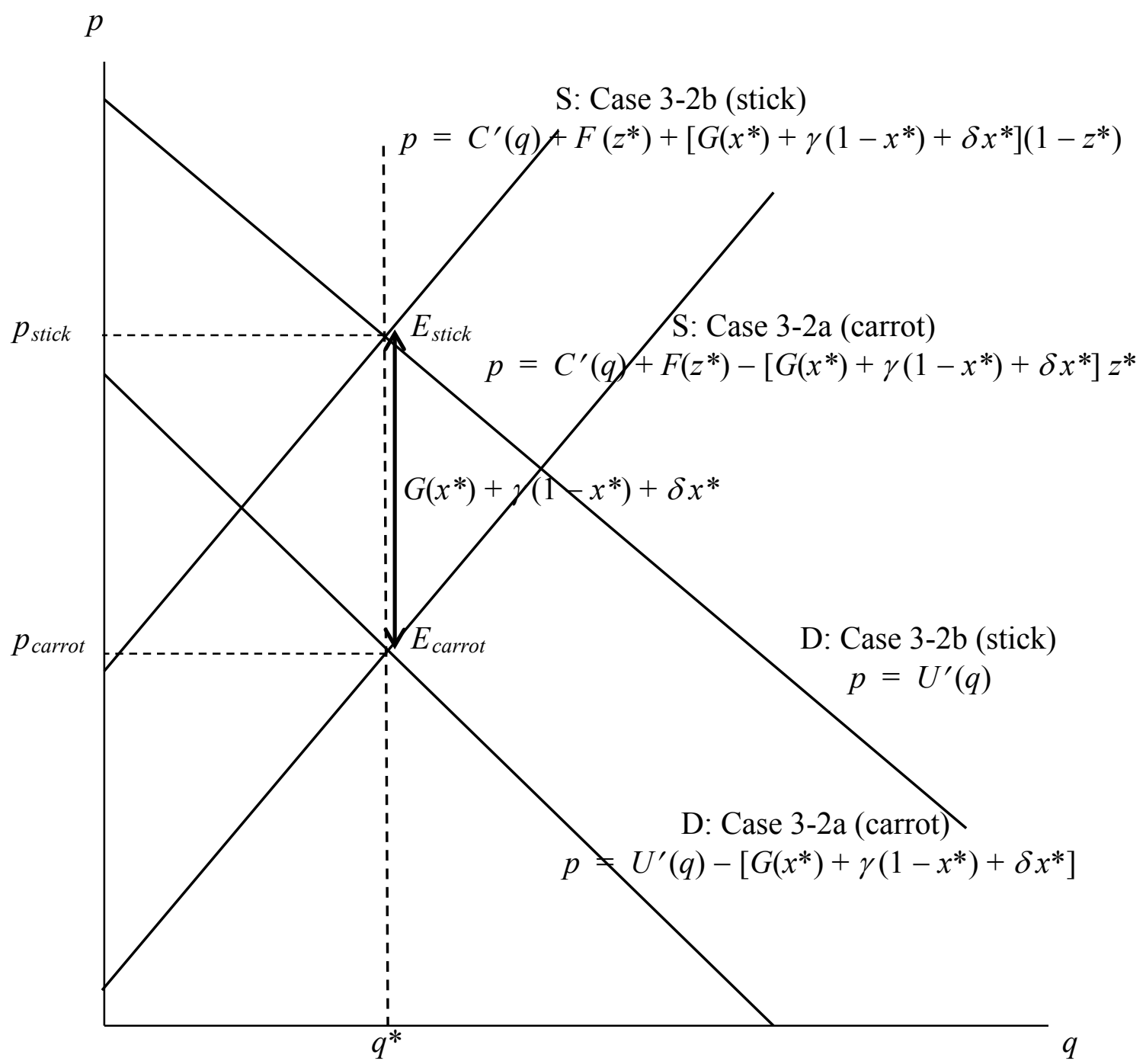

Note: For 3-2a, D curve given by (10a) and S curve given by (8a). For 3-2b, D curve given by (10b) and $\mathrm{S}$ curve given by (8b). 
Figure 2. Packaged good market - without a waste charge

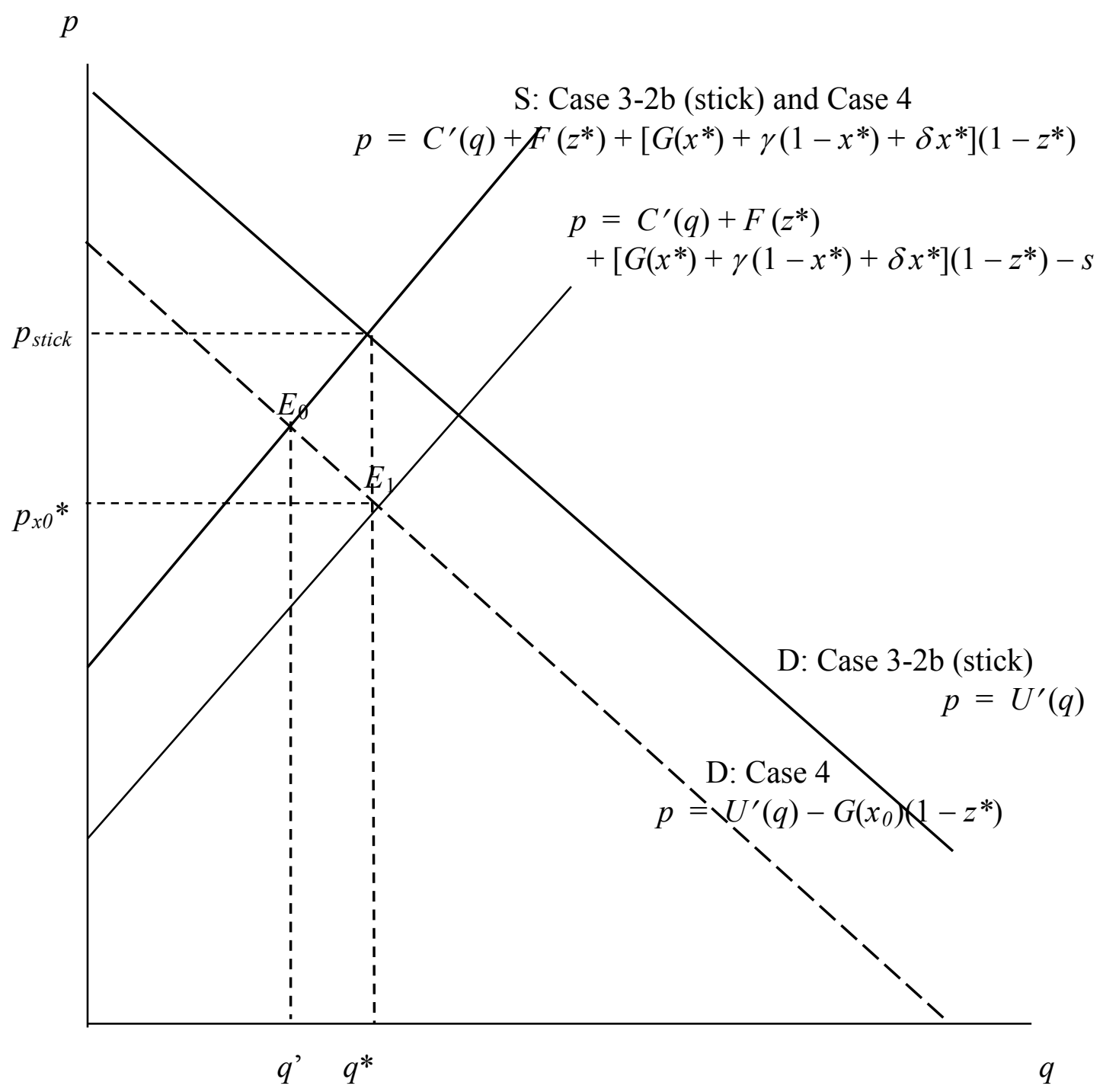


Table 1. Cases 3-1

Case 3-1a

Case 3-1b

Case 3-1c

Demand side $\phi=\gamma-\delta$ and $\tau_{D}=0 \quad \phi=0$ and $\tau_{D}=\gamma-\delta$ $\tau_{D}=\gamma$ and $\phi=-\delta$

Supply side $\tau_{S}=\gamma$ $\tau_{S}=\delta$ nothing

Table 2. Cases 3-2

Demand side

$$
\begin{aligned}
& \phi=\gamma-\delta \text { and } \\
& t=G\left(x^{*}\right) z^{*}+(\delta-\gamma) x^{*} z^{*}+\gamma \\
& \text { per unit } q^{\dagger}
\end{aligned}
$$

$$
\begin{aligned}
& \phi=\gamma-\delta \text { and } \\
& s=\left[G\left(x^{*}\right)+(\delta-\gamma) x^{*}\right]\left(1-z^{*}\right) \\
& \text { per unit } q^{\dagger}
\end{aligned}
$$

Supply side

$$
\sigma=G\left(x^{*}\right)+\gamma\left(1-x^{*}\right)+\delta x^{*}
$$$$
\tau=G\left(x^{*}\right)+\gamma\left(1-x^{*}\right)+\delta x^{*}
$$

\footnotetext{
${ }^{\dagger}$ The product tax or subsidy can be imposed on either party in the product market.
} 